\title{
O PAPEL DA CERTIFICAÇÃO AMBIENTAL NA CONSECUÇÃO DO DESENVOLVIMENTO E CONSUMO SUSTENTÁVEL
}

\author{
THE ROLE OF ENVIRONMENTAL CERTIFICATION IN GUARANTEEING \\ SUSTAINABLE DEVELOPMENT AND CONSUMPTION
}

Tatiana de Almeida Freitas Rodrigues Cardoso Squeff ${ }^{1}$

\begin{abstract}
Resumo: O presente artigo tem como objetivo debater a certificação ambiental. Inicialmente busca-se expor o seu surgimento no plano internacional no campo do Direito Ambiental Internacional enquanto ferramenta de gestão ambiental. Na sequência, explica-se a relevância da certificação ambiental a partir das ferramentas econômicas, especificamente notando-a enquanto uma externalidade positiva a qual deve ser introduzida nos custos de transação, momento em que se passa a agregar valor aos bens de mercado devidamente certificados. Por fim, trabalha-se com os pontos positivos e negativos da adoção dos "selos" ambientais, concluindo-se que, muito embora haja aspectos negativos, a certificação é uma ferramenta importantíssima para a consecução do desenvolvimento e do consumo sustentável, vez que ela ajuda a imprimir uma nova racionalidade no que tange a utilização dos recursos naturais, típica da contemporaneidade, alertando para a sua esgotabilidade e para a necessidade de se adotarem medidas que combatam esse problema oriundo da modernidade. Assim, sobre o tema realizou-se, a partir do método dedutivo, uma pesquisa descritiva, de natureza aplicada, utilizando-se dos procedimentos bibliográfico e documental, selecionados qualitativamente, em que pese sem o condão de exauri-los.
\end{abstract}

Palavras-chave: Certificação ambiental; Externalidades positivas; Desenvolvimento sustentável; Consumo sustentável.

\begin{abstract}
The purpose of this article is to discuss environmental certification. Initially it seeks to expose its emergence at the international level in the field of International Environmental Law as an environmental management tool. Subsequently, the importance of environmental certification from the economic tools is explained, specifically noting it as a positive externality, which must be introduced in the transaction costs, at which point value is added to duly certified market goods. Finally, the positive and negative points of adopting environmental "labels" are debated, concluding that, although there are negative aspects, certification is a very important tool for the achievement of sustainable development and consumption, since it helps to create a new rationality regarding the use of natural resources, typical of contemporaneity, warning of its exhaustion and noting the need to adopt measures to combat this problem arising from modernity. Thus, on the subject, a descriptive research, of an applied nature, using the bibliographic and documentary procedures, selected qualitatively, was carried out, based on the deductive method, in spite of the fact that it
\end{abstract}

1 Professora permanente do Programa de Pós-graduação em Direito e Professora Adjunta de Direito Internacional da Universidade Federal de Uberlândia - UFU. Expert brasileira nomeada pelo Ministério da Justiça/SENACON para atuar junto à Conferência de Direito Internacional Privado da Haia - HCCH, no Projeto Turista. Doutora em Direito Internacional pela Universidade Federal do Rio Grande do Sul UFRGS, com período sanduíche junto à University of Ottawa. Mestre em Direito pela Universidade do Vale do Rio dos Sinos - UNISINOS, esta com bolsa CAPES e período sanduíche junto à University of Toronto, com bolsa DFAIT. Especialista em Língua Inglesa pela Unilasalle, em Direito Internacional pela UFRGS - PPGD e em Relações Internacionais Contemporâneas pela UFRGS - PPGEEI. Possui aperfeiçoamento em direito Norte-Americano (Fordham University), Direito Humanitário (Harvard University), instituições econômicas internacionais (New York University), Refugiados (York University) e Direito Internacional Público (Hague Academy - 2013, 2017 e 2019 - esta com bolsa). E-mail: tatiafrcardoso@gmail.com 
was not able to exhaust them.

Keywords: Environmental certification ; Positive externalities; Sustainable development; Sustainable consumption.

\section{INTRODUÇÃO}

A certificação é um tema que tem ganhado grande destaque na sociedade, especialmente pelo crescente número de "selos" que brotam nos mais diversos foros nacionais e globais, os quais trazem consigo benefícios de ordem não só econômica para as empresas que os adotam, as quais constantemente veem-se diante de um consumidor cada vez mais exigente, como também para os próprios indivíduos em razão da facilidade de identificar produtos que correspondem aos seus anseios - isso sem contar os próprios desdobramentos que estes podem ter na seara ambiental, em relação à tutela do meio ambiente sadio e equilibrado pela adoção de práticas sustentáveis na produção.

Em vista disso, o presente texto visa primeiramente debater as origens da certificação ambiental, na tentativa de demonstrar a íntima relação que os "selos" apresentam para com o consumo sustentável, assim como com o próprio mandamento do desenvolvimento sustentável - conceitos esses que brotaram do "desenvolvimento e do crescimento predatório dos Estados", os quais "atrelado[s] à globalização econômica, aumenta[r]am o risco, em matéria ambiental”, demandando a instituição de novos pressupostos voltados à coibir o exaurimento dos recursos naturais e a alterar os padrões de consumo da ordem mundial (GUERRA: 2006 ${ }^{\mathrm{a}}$; p. 15).

Afinal, se "as transformações provocadas no planeta Terra pode[m] comprometer a vida de todos os seres humanos, [...] uma mudança de comportamento e dos paradigmas existentes no âmbito da sociedade global" mostra-se verdadeiramente necessária (GUERRA: 2006 ; p. 14). Outrossim, considerando as imbricações naturais entre o ser humano, a natureza e a economia, nada mais natural em pensar alternativas que nasçam deste tripé.

Em vista disso, após o exame acerca das origens da certificação ambiental no Direito (Ambiental) Internacional, o texto volta-se à apreciação dos fundamentos econômicos que explicam a necessidade de criarem-se ferramentas que possam ajudar a "demover as pessoas de seus [antigos] hábitos de consumo [irracional], alterar radicalmente [o uso de] matrizes energéticas fósseis, [...] investir os recursos hoje disponíveis na recuperação de ambientes degradados", dentre outros, colaborando para a realização de práticas sustentáveis (GUERRA: 2006 ; p. 15). Assim, verificar-se-ão os "selos" ambientais como sendo alternativas possíveis voltadas a esse fim à luz da ciência econômica, aproximando-as do Direito através da análise econômica.

Por fim, a última parte deste estudo dedica-se a ponderar acerca dos lados positivos da implementação da certificação ambiental, assim como os negativos. Isso porque, por mais que exista a "necessidade de [realizarem-se] ações estratégicas no sentido de reduzir os riscos ambientais no complexo equilíbrio com os interesses econômicos", exige-se a apreciação de todas as vertentes deste mecanismo, para que seja possível dizer, ao cabo, se, de fato, os "selos" apresentam um papel de destaque na consecução do desenvolvimento e consumo sustentável (GUERRA: 2006; ; p. 16).

Assim, no que tange aos aspectos metodológicos, a partir do método dedutivo, realiza-se uma pesquisa de natureza aplicada, seguindo o modelo descritivo, inicialmente desde um viés histórico, 
seguido por uma revisão crítica sobre a certificação ambiental. Para tanto, utiliza-se dos procedimentos bibliográfico e documental, selecionados e abordados qualitativamente, em que pese não se tenha o condão de exauri-los (GERHARDT; SILVEIRA: 2009).

\section{DO DESENVOLVIMENTO SUSTENTÁVEL AO CONSUMO SUSTENTÁ- VEL: AS BASES PARA O SURGIMENTO DA CERTIFICAÇÃO AMBIENTAL}

A proteção do o meio ambiente nem sempre esteve no centro das atenções do ser humano, especialmente quando este utilizara dos recursos ambientais para a sua plena satisfação, sem quaisquer considerações acerca da sua finitude e esgotabilidade. Particularmente no âmbito da revolução industrial, a sociedade atrelava-se à suposição econômica neoclássica de crescimento infinito, cujo conceito principal era apenas de produzir e fomentar o consumo, até mesmo porque, a exaustão dos bens ambientais não figurava dentre os possíveis resultados (DAUVERGNE; CLAPP: 2005; p. 10).

Esse cenário, todavia, conduziu a humanidade ao uso desenfreado e irracional dos recursos naturais, os quais, na época contemporânea (ou pós-moderna), somado ao avanço tecnológico, acentuaram os danos ao meio ambiente e o consumo acelerado dos recursos naturais. Assim sendo, ao lado do desenvolvimento econômico, problemas de ordem ambiental terminaram por ser cada vez mais recorrentes, de modo que a conexão entre os campos econômico e ambiental não podiam mais ser dissociados.

Noutros termos, as consequências da industrialização já não passariam mais desapercebidas pela sociedade mundial, a qual começou a questionar os limites do desenvolvimento econômico quando consideradas as consequências de ordem ambiental que ele gera, tanto para a ordem doméstica quanto internacional. Afinal, os danos não respeitam as fronteiras nacionais, possivelmente apresentando reflexos em outras nações, tal como ocorre quando há a poluição do ar e de rios transfronteiriços, a degradação do solo, o desmatamento desenfreado e a perda de biodiversidade, para citar alguns exemplos (CARVALHO: 2011; p. 32-94).

Particularmente, os resultados parciais de uma exploração desenfreada denotam a possibilidade de limitação do próprio crescimento econômico em razão do esgotamento ou inaptidão do bem ambiental utilizado para tal. E justamente essa possibilidade fez com que os países se reunissem em 1972, na cidade de Estocolmo, para debater as consequências da exploração econômica sobre o meio ambiente, na tentativa de "livrar o homem e da ameaça de sua escravidão diante dos perigos que ele próprio criou para o meio ambiente", como afirmou Maurice Strong, Secretário Geral da Conferência realizada sob os auspícios das Nações Unidas, na conferência de abertura do evento (GUERRA: 2009; p. 496).

A Conferência de Estocolmo, ponto marcante para o desenvolvimento do Direito Ambiental Internacional, tinha como objetivo estruturar "critérios e princípios que pudessem ser comuns para a preservação e melhoria do meio ambiente humano", frente a sua exploração. Apesar disso, importante ressaltar que a posição dos países do Norte global - formado por países desenvolvidos - acerca dessa tentativa não compartilhada pelos países do Sul - formado por países em desenvolvimento -, revelando "uma forte divergência entre as [suas] percepções ambientais" (GUERRA: 
2009; p. 496). Isso porque, "as opiniões dos países em desenvolvimento baseavam-se na premissa de que os problemas ambientais eram preocupações apenas para as nações altamente desenvolvidas [...] sendo consideradas como um modo de burlar o desenvolvimento dos mesmos" (ROWLAND: 1973; p. 47).

Em outras palavras, a racionalidade das nações de Norte e Sul no que compete às suas ambições frente ao meio ambiente, naquela época, eram particularmente distantes: os países em desenvolvimento não se preocupavam com os problemas ambientais, mas tão-somente com seu desenvolvimento econômico, enquanto os países desenvolvidos almejavam ver-se livres das dificuldades que poderiam ser inseridas nas suas fronteiras pelo descaso dos demais.

O representante da Costa do Marfim da Conferência de 1972, por exemplo, chegou a afirmar que se a poluição trouxesse o desenvolvimento e a industrialização ao seu país, estes estariam dispostos a aceitar os riscos (BRETTON: 1994; p. 39). A da representação brasileira, por sua vez, afirmara que a poluição seria um problema de nações desenvolvidas, não devendo ser tratada de modo idêntico por todos os Estados (D’AMATO; ENGEL: 1997; p. 14). Posições estas que estavam assentadas na possiblidade que os países desenvolvidos tiveram anteriormente em evoluir, os quais, por meio de limites ambientais, barrariam as chances dos países em desenvolvimento em alcançar níveis semelhantes.

Com isso, nota-se que a constatação de que a exploração econômica poderia ser restrita pela degradação ao meio ambiente por ela causada não foi automática, mas sim fruto de debates na ordem internacional, os quais foram aquiescidos pela sociedade como um todo quando esta também se deparou com outra consequência oriunda dos danos ambientais, qual seja, o impacto social. Afinal, não só o empreendimento se vê restringido economicamente quando o recurso natural deixa de existir ou se encontra limitado em razão do seu uso irracional, como o próprio ser humano pode ser igualmente impactado pela degradação oriunda da exploração.

Exemplo dessa situação é a poluição das águas, tal como a "descoberta da intoxicação com mercúrio de várias comunidades na região de Minamata (Japão) entre 1954 e 1965, por força das descargas realizadas por uma fábrica de elementos químicos no mar, contaminado os peixes da região", assim como a populações que os consumia, deixando "multidões com sequelas neurológicas irreversíveis e levou outras muitas à morte" (SQUEFF: 2016; p. 12). Nesse caso, a exploração desenfreada do recurso natural gerou um impacto não só de natureza ambiental, pela inexistência de peixes a serem pescados em tal região, limitando, consequentemente, a operação econômica, mas também trouxe reflexos ao ser humano, o qual teve a sua saúde atingida em função da realização da atividade econômica.

Inclusive, é em razão desse outro impacto que na Conferência de 1972 igualmente observou-se a formulação do meio ambiente sadio e ecologicamente equilibrado como condição prévia essencial para a vida e o bem-estar humano, e para o consequente gozo completo dos direitos básicos não só da geração presente, mas também das vindouras. Essa integração vem explícita no documento acordado ao fim das discussões, tanto em seu preâmbulo quanto no seu primeiro e segundo princípio, respectivamente (ONU: 1972): 
O homem é ao mesmo tempo obra e construtor do meio ambiente que o cerca, o qual lhe dá sustento material e lhe oferece oportunidade para desenvolver-se intelectual, moral, social e espiritualmente. [...] Os dois aspectos do meio ambiente humano, o natural e o artificial, são essenciais para o bem-estar do homem e para o gozo dos direitos humanos fundamentais, inclusive o direito à vida mesma (preâmbulo - 1).

A proteção e o melhoramento do meio ambiente humano é uma questão fundamental que afeta o bem-estar dos povos e o desenvolvimento econômico do mundo inteiro, um desejo urgente dos povos de todo o mundo e um dever de todos os governos (preâmbulo - 2).

$\mathrm{O}$ homem tem o direito fundamental à liberdade, à igualdade e ao desfrute de condições de vida adequadas em um meio ambiente de qualidade tal que lhe permita levar uma vida digna e gozar de bem-estar, tendo a solene obrigação de proteger e melhorar o meio ambiente para as gerações presentes e futuras (princípio I).

Os recursos naturais da terra incluídos o ar, a água, a terra, a flora e a fauna e especialmente amostras representativas dos ecossistemas naturais devem ser preservados em benefício das gerações presentes e futuras, mediante uma cuidadosa planificação ou ordenamento (princípio II).

Desta feita, da Declaração de Estocolmo, como é comumente conhecido esse extrato final da Conferência de 1972, é que se percebe a interligação entre os campos econômico - social - ambiental, o qual não mais apresenta o primeiro como eixo central, mas sim o último, posto que é ele, ao fim e ao cabo, que pode determinar a existência de uma vida saudável e o contínuo exercício de uma atividade econômica.

Outrossim, a formulação do desenvolvimento sustentável (tripé formado pelas três vertentes acima destacadas) como objetivo a ser alcançado pela atividade humana, não pode ser atribuído à Conferência de 1972. Esta ação coube à Cúpula da Terra, conferência realizada na cidade do Rio de Janeiro em 1992.

Se anteriormente as contendas giravam em torno das diferenças entre as nações, principalmente na ideia de que o meio ambiente poderia barrar o desenvolvimento econômico, o que fazia das medidas verdes impraticáveis pelos interesses dos países, nesse foro internacional o cerne foi justamente que essas três vertentes deveriam ser conjuntamente praticadas (BATEMAN; PEARCE; TURNER: 1993; p. vii). Ou seja, a Conferência do Rio já assimilava as articulações entre os planos econômico, ambiental e social; porém, apontava ainda para a aplicação do desenvolvimento sustentável por todos os Estados para tentar reverter os efeitos da degradação ambiental, almejando conduzir o cenário mundial a uma soma positiva, onde todos absorveriam benefícios, pois agiriam de maneira verdadeiramente cooperada em prol de ações economicamente, ambientalmente e socialmente sustentáveis (ONU: 1989).

Afinal, o referido mandamento estabelece que a exploração econômica dos bens ambientais seja realizada considerando a sua finitude/saturação, devendo levar-se em consideração o tempo e a capacidade de regeneração necessária para que o bem possa ser continuamente utilizado ao longo dos anos em prol do progresso humano e por todos os humanos, sem os quais prejuízos incalculá- 
veis podem ser gerados à sociedade nacional/mundial, hoje ou no futuro, pelo comprometimento de sua capacidade de satisfazer os seus interesses básicos. ${ }^{2}$

É por isso que a Conferência do Rio, convocada igualmente pelas Nações Unidas ${ }^{3}$ após a edição do Relatório da Comissão Mundial para o Meio Ambiente e Desenvolvimento em $1987^{4}$ em que se utilizava pela primeira vez da expressão 'desenvolvimento sustentável', reunindo as delegações de 192 países, além de 10.000 jornalistas e representantes de 1.400 organizações não-governamentais, foi fundamental (LAGO: 2007; p. 52), pois ela altera a racionalidade dos diversos atores internacionais, tornando cada vez mais explícito o esgotamento dos recursos naturais e os seus consequentes impactos de ordem econômica e social, para todas as gerações, ao redor do globo.

Não só isso, os “documentos [firmados nessa Conferência, além de] definir[e]m o contorno das políticas essenciais para alcançar o modelo de desenvolvimento sustentável que atendesse às necessidades dos [países mais] pobres, reconhece[ram] [também] os limites de desenvolvimento [de cada nação], de modo a satisfazer às necessidades globais”. Assim, assentou-se nesse encontro o princípio da 'Responsabilidade comum, porém, diferenciada', o qual supera as discussões havidas em Estocolmo por abordar a questão da equidade, tratando diferentemente os países que menos e mais contribuíram mais para o estado de degradação ambiental corrente, garantindo melhores condições àqueles que no passado não colaboraram (tanto) para o quadro atual (YU: 2004; p. 53 $54)$.

Nesse escopo, países do Norte global teriam mais responsabilidades para com a sua produção, haja vista terem tido a oportunidade de desenvolverem-se sem quaisquer restrições, tais como aquelas impostas pelo mandamento do desenvolvimento sustentável. Inclusive, essas responsabilidades diferenciadas as quais impõe encargos maiores aos países desenvolvidos contemplam outros mandamentos, como o do consumo sustentável, haja vista o seu maior potencial produtivo advindo do seu estado avançado de desenvolvimento econômico-tecnológico.

Este último mandamento também é originário da Conferência de 1992, tendo sido ventilado quando se alertou que uma das maiores causas da deterioração do meio ambiente em nível mundial

2 Nas palavras de Guerra: "Busca-se com [o desenvolvimento sustentável] a coexistência harmônica e proporcional entre economia e meio ambiente, permitindo-se o desenvolvimento de forma sustentável, planejada, para que os recursos hoje existentes não se esgotem ou se tornem inócuos, isto é, o desenvolvimento sustentável é o princípio que busca encontrar o equilíbrio entre a atividade econômica e o uso adequado, racional e responsável dos recursos naturais para as gerações atuais e futuras" (GUERRA: 2006b; p. 446). 3 Foram várias as reuniões promovidas pelas Nações Unidas sobre a temática ambiental, por intermédio de sua Assembleia Geral. A primeira, de fato, foi a Conferência de Estocolmo em 1972, a qual foi seguida por outra em Nairóbi em 1982. Após é que se promoveu a Cúpula da Terra no Rio de Janeiro em 1992 em comento, sendo essa seguida pela Rio +5 , em Nova Iorque em 1997, e pela Conferência de Johanesburgo em 2002. Por fim, em 2012, realizou-se a Rio + 20, também na cidade do Rio de Janeiro. Para um apanhado acerca de cada um dos referidos encontros, excluído o de 2012, cf. GUERRA: 2006; ; p. 96-109).

4 Também conhecido como "Nosso Futuro Comum" ou "Relatório Brundtland" em homenagem à ex-primeira ministra da Noruega, Gro Harlem Brundtland, que presidiu a referida Comissão, constituída enquanto um desdobramento da Conferência de 1972 no ano de 1983. Ressalta-se que 'desenvolvimento sustentável', no entendimento da Comissão, seria "o desenvolvimento capaz de manter o progresso humano não apenas em alguns lugares por alguns anos, mas em todo o planeta ate um futuro longínquo" (GUERRA; GUERRA: 2013; p. 238). 
era a não adoção de padrões sustentáveis de produção e consumo. Ele se refere a "um nível de consumo que gera um nível de impacto ambiental ao longo do tempo o qual não degrada os ecossistemas", seja por utilizar menos recursos naturais em sua produção, seja por permitirem a sua reutilização através da reciclagem, o qual se atenta também pela qualidade do emprego ${ }^{5}$ gerado na sua fabricação (SALZMAN: 1997; p. 1246).

Noutros termos, o consumo sustentável implica no emprego de atividades que, na produção, no uso ou em um eventual descarte, "são, simultaneamente, socialmente relevantes, ecologicamente prudentes e economicamente viáveis” (RAMOS; SQUEFF: 2019; no prelo). Portanto, ele está intimamente ligado ao desenvolvimento sustentável, surgindo como seu complemento - uma consequência - exatamente por rechaçar a adoção de práticas que podem impactar diretamente naquele por igualmente gerarem problemas de ordem econômico-social (aumentando/diminuindo o valor do bem) e ambiental (promovendo a degradação e o uso irracional do bem ambiental), sem haver um equilíbrio entre a atividade econômica e o uso adequado dos recursos.

Questões essas que são centrais para compreender o surgimento das certificações ambientais, as quais emergem justamente para garantir comprovadamente ao consumidor que determinado bem foi produzido à luz do mandamento do desenvolvimento sustentável, permitindo, por consequência, que o consumo também o seja, suprindo essa demanda crescente da sociedade contemporânea, cada vez mais preocupada com os bens ambientais sob o viés intergeracional (TRINDADE: 1993; p. 23), buscando satisfazer as suas necessidades de maneira ambientalmente correta frente às consequências da modernidade 6 .

Isso porque, de maneira sucinta, a certificação refere-se a "um processo de verificação por uma terceira parte emissora do certificado de que determinada empresa atua de acordo com certos critérios uniformes em relação ao meio ambiente, estabelecidos numa norma técnica" (CORREAA: 2006; p. 194). Logo, refere-se à concessão de um "selo" por entidade independente, nacional ou internacional, que atesta positivamente que determinado produto está de acordo com certas normativas previamente estabelecidas, permitindo que o consumidor possa agir racionalmente, conforme suas convicções e preferências.

Explicitamente, as certificações ambientais foram citadas como instrumentos capazes de implementar o desenvolvimento sustentável ainda na Agenda 21, documento sem força obrigatória forjado ao final da Conferência do Rio de Janeiro destinado a guiar os Estados na consecução de suas obrigações assumidas em nível internacional, prescrevendo, para tanto, sugestões de mecanismos passíveis de serem utilizados (CORRÊA: 2006; p. 194). Mais especificamente, elas foram citadas no Capítulo 7 do referido documento, voltado à promoção do desenvolvimento sustentável dos assentamentos humanos, enquanto mecanismos passíveis de colaborar para a preparação/ transformação da cadeia produtiva deste setor, fomentando que estes realizassem as adequações

5 Acerca disso, porém, explica Guerra que, na atual era da globalização, os direitos sociais são inegavelmente a área que mais sofrera grandes consequências, especialmente em países periféricos, sendo cada vez mais comum a redução de custos salarias, implicando, consequentemente, na diminuição progressiva dos direitos atinentes ao trabalho em detrimento de sua melhora. $C f$. GUERRA: 2018; p. 225-227.

6 Para dialogar com Giddens, em relação aos riscos que estaríamos sujeitos atualmente, tais como a degradação ambiental cada vez mais crescente, entre tantos outros problemas e calamidades em potencial. $C f$. GIDDENS: 1991; p. 126-128. 
necessárias no processo de construção para atingirem o desenvolvimento (e o consequente consumo) sustentável (BRASIL, s/d).

Outrossim, nada impede que essas certificações ambientais sejam utilizadas em outros setores da economia para fomentar a modificação das práticas produtivas, efetivando os mandamentos de sustentabilidade de desenvolvimento e consumo. Por isso, na seguinte seção, procurar-se-á debater os fundamentos teóricos para a adoção das certificações, na tentativa de demonstrar o papel importante que elas detêm para a proteção do meio ambiente humano pela internalização de externalidades.

\section{CERTIFICAÇÃO AMBIENTAL: AGREGANDO VALOR AOS BENS DE MERCADO EM TROCA DE CONDUTAS SUSTENTÁVEIS}

A certificação ambiental enquanto procedimento "sistematizado de acompanhamento e avaliação de que um produto, processo ou serviço atende a requisitos preestabelecidos em normas e regulamentos técnicos com o menor custo [ambiental] para a sociedade", objetiva "informar e proteger o consumidor, propicia[ndo] a concorrência justa [e] estimula[ndo] a melhoria contínua da qualidade [dos bens]" (NUNES: 2018; p. 32). Ela decorre da impossibilidade de o consumidor, por si, verificar se o bem atingiu os padrões mínimos buscados por ele (FARINA: 2003; p. 21).

Assim sendo, através da concessão de um "selo" por determinada entidade, a qual é normalmente privada ${ }^{7}$, o bem em questão não apenas colaboraria para se atingir o desenvolvimento e o consumo sustentável para o qual eles foram concebidos, como também promoveria uma busca pelos concorrentes por padrões similares a fim de que estes não percam espaço no mercado de consumo, colaborando para um constante aprimoramento das práticas empresariais atinentes à produção e a para a manutenção do meio ambiente sadio e equilibrado para as gerações presentes e futuras.

Nesse viés, nota-se que a atribuição do citado "selo" faz com que esse produto influencie a escolha do consumidor no mercado, fazendo com que o bem adquira uma vantagem em detrimento dos demais, de modo que ele passará a ser o "predileto" dentre os componentes de certo grupo de consumidores racionalmente preocupados com a temática da sustentabilidade ${ }^{8}$ e adquirentes de tal

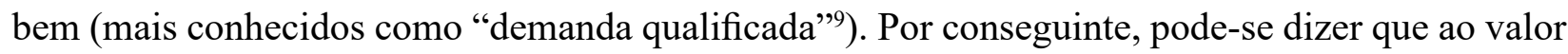
intrínseco do bem é economicamente majorado em razão da atribuição do referido certificado, sem

7 Segundo Lima, a pluralidade de atores jurídicos, os quais incluem pessoas do âmbito privado de atuação (para além de estes públicos estatais), cujo exemplo seriam essas entidades certificadores, seria um dos efeitos da globalização do direito, a qual tende a aceitar a coexistência de ordens jurídicas distintas e conduz a fragmentação do direito e a descentralização do poder. (Cf. LIMA: 2012; p. 38).

8 Nem todo ser humano é racionalmente preocupado com essa temática, de modo que a falta de racionalidade "voltada para uma visão biocêntrica, preocupada com todos os seres que a cercam, além de verificar que o ser humano não é dono e senhor de tudo e, sim, parte do todo, além, de ser extremamente dependente das relações ecossitêmicas" seria o mais comum (CALGARO: 2006).

9 A demanda qualificada foge da perspectiva tradicional realizada pela Análise Econômica, de que os seres humanos fazem cálculos "para alcançarem os maiores benefícios aos menores custos" - chamado de maximização racional. Nesse caso, os indivíduos "farão escolhas que atendam seus interesses pessoais, sejam esses interesses quais forem", mesmo que isso implique em um custo maior (SALAMA: 2008; p. 54). 
o qual, por outro lado, o produtor não teria como comprovar que o seu bem atinge as expectativas de determinados consumidores.

Tal majoração corresponderia à internalização das externalidades (positivas) ambientais geradas pelo produtor quando da fabricação do bem de consumo, reconhecendo a sua preocupação com o meio ambiente e a sociedade, e, logo, proporcionando-lhe uma contraprestação por tal atitude. Conforme aduz Alexandre Morais da Rosa, externalidades "são consequências positivas ou negativas decorrentes das ações dos sujeitos em face de terceiros não intervenientes nas transações originárias" (ROSA: 2011; p. 43).

Quer isto dizer que elas não compõem o apuramento dos custos de transação ${ }^{10}$ entre as partes negociantes precisamente porque há casos em que outro(s) agente(s) resta(m) ofendido(s) ou beneficiado(s) por uma conduta lícita, com a qual não deté(ê)m qualquer tipo de relação - o que pode lhe(s) gerar um prejuízo ou um acréscimo (HARRISON: 2000; p. 42-44). Assim, a realidade não seria refletida apenas de altos/baixos custos de transação, mas também de custos externos não internalizados.

Acerca das externalidades, dissertam Cristiano Carvalho e Eduardo Jobim (2008; p. 241):

As externalidades são perdas ou ganhos não internalizados pelos produtores e consumidores e que, portanto, não integram o cálculo dos custos e preços das mercadorias, bens e serviços. Exemplos clássicos é a fábrica que polui o ambiente, ou a boate que produz barulho para a vizinhança ou então a residência que contrata o serviço de vigilância, do qual as demais residências acabam se beneficiando (free riders) sem contribuir para com o custo necessário. Os dois primeiros exemplos são externalidades negativas, enquanto o último é uma externalidade positiva.

Neste passo, afirma-se que as externalidades correspondem ao impacto social de uma determinada ação do mercado, os quais não são registrados pelos agentes econômicos, sendo, por isso, dificilmente agregadas ao cálculo do custo de transação desses bens e/ou serviços, em que pese usufruídas por outrem (free riders).

Normalmente, eles se manifestam na sociedade ao passo que infringem os limites legais de terceiros, os quais sofrem prejuízos pelos quais não são compensados (isto é, arcam com os seus

10 "Os custos de transação [também chamados de custos sociais] estão diretamente envolvidos com as escolhas racionais realizadas pelos agentes econômicos para gerenciar os recursos e gerir a produção, sejam eles internos (no seio das instituições) ou externos (relativos ao mercado). Os custos fornecem informações importantes para as diferentes etapas de uma determinada transação econômica, influenciando diretamente a tomada de decisão. Dizem respeito a um valor de determinada 'unidade de atividade', a qual será avaliada e negociada pelas partes envolvidas em função do intercâmbio econômico que pretendem concretizar, antes de qualquer deliberação. Envolvem desde os custos de busca para escolher/encontrar um interessado na transação, os custos do arranjo negocial, como aqueles alusivos à formulação de um contrato e à reunião com a parte contrária, e até mesmo os custos de execução. São exemplos (não exaustivos) desta última espécie as estimativas referentes à adoção de uma nova tecnologia, ao treinamento de empregados, a fiscalização, a dispensa ou contratação de um serviço, à adoção de medidas preventivas, ao aumento ou diminuição de horas trabalhadas, a manutenção ou diminuição de uma área verde, ao tempo dispensado, a qualidade ou quantidade de um insumo, enfim, a todo o processo de implementação de um determinado produto ou serviço. Calcular os custos de transação, portanto, é imprescindível, dado que a sua subestimação pode impactar negativamente um negócio" (SQUEFF: 2016; p. 103-104). 
custos), exatamente por não terem participado da transação. Acerca disso, importante destacar a passagem de Fábio Nusdeo (2010; p. 153):

\begin{abstract}
As externalidades correspondem, pois, a custos ou benefícios circulando externamente ao mercado, vale dizer, que se quedam incompensados [...]. E, assim, o nome externalidade ou efeito externo não quer significar fatos ocorridos fora das unidades econômicas, mas sim fatos ou efeitos ocorridos fora do mercado, externos ou paralelos a ele, podendo ser vistos como efeitos parasitas.
\end{abstract}

Assim, dever-se-ia corrigir esse problema para restaurar a ineficiência de dada realidade, de modo que se internalizem as externalidades. ${ }^{11}$ Ao mesmo tempo, a sua retificação é importante para a garantia da própria sustentabilidade, dado que tais custos, quando negativos, afetam a sua efetividade, particularmente em razão do uso desenfreado dos bens comuns por certos atores, os quais procuram maximizar os seus ganhos, mesmo que isso signifique a escassez total de determinado recurso de uso comum no futuro.

Já no caso da certificação ambiental, como aludido supra, trata-se de é uma externalidade positiva, vez que os demais indivíduos (free riders), mesmo que não optem por determinado produto, ganham com a menor degradação ambiental. Com isso, se a internalização dos custos sociais parece importantíssima para que os participantes diretos de determinado negócio não carreguem sozinhos os fardos da degradação no caso de externalidades negativas, quando se trata de externalidades positivas, parece igualmente relevante falar na internalização dos “custos" havidos em razão da implementação de tal prática benéfica.

E justamente uma forma de colaborar para com a manutenção dessas ações benéficas ao meio ambiente é o que a certificação traz, posto que ela "chancela" a possibilidade de determinado produtor cobrar mais por seu produto ambientalmente correto. Por conseguinte, tem-se que a certificação ambiental é uma das maneiras possíveis, conforme a Ciência Econômica, de retificar as externalidades, qual seja, a Coaseana, ligada a uma solução eficiente, onde os direitos de propriedade estão bem definidos, isto é, individualizados (em detrimento da existência de bens comuns ${ }^{12}$ ), proposta por Ronald Coase.

Coase entende que a intervenção do Estado não é necessária para a correção das externalidades, acreditando na negociação entre as partes para atingir uma solução eficiente. O custo social seria resolvido pelo próprio mercado, em que o valor "das externalidades é livremente negociado entre as partes diretamente interessadas" e os efeitos por elas gerados são financeiramente neutralizados (REALI: 2006; p. 48). Com efeito, segundo essa tese, percebe que ambos os agentes econômicos podem acabar arcando com as externalidades, dependendo tão-somente da capacidade

11 Destaca-se a passagem de Gustavo Silveira e Renata Amaral (2008; p. 289) acerca dos efeitos dos custos sociais negativos: “A externalidade negativa [...] produz um efeito negativo em outra pessoa, afetando o bem-estar ou os lucros desta, não sendo naturalmente compensada pelo agente causador. [...] A falta de internalização dos seus efeitos negativos só faz aumentar o lucro dessas atividades econômicas e diminuir a renda e a qualidade de vida das populações".

12 "Em Coase é encontrando o pensamento categórico: 'tudo que não pertence a ninguém é usado por todos e cuidado por ninguém'. Daí a sua proposta consistir em transformar tudo que for de propriedade comum em direito de propriedade individual (property rights)" (DERANI: 2009; p. 91). 
financeira do agente, sendo impossível, de imediato, imputar a compensação monetária ao causador direto do dano ou ao criador de beneficio (COASE: 1960; p. 2-3) (COASE: 2000; p. 552-553).

Afinal, como bem lembra David Friedman (1992; p. 35), “[...] o custo não é simplesmente imposto por uma parte à outra, antes decorre de atividades incompatíveis prosseguidas pelas duas partes". Quer isso dizer que, no caso de externalidades positivas, o aumento do bem-estar a partir da adoção de prática ou medida esverdeada pode gerar, sim, a possiblidade do produtor em questão aumentar o valor do seu produto, em que pese o montante ser variável haja vista a capacidade financeira daqueles que irão adquiri-lo.

Apesar disso, cumpre salientar que, em tal panorama, não haveria lugar para o Direito influir na tomada de decisão (preço), visto que independente do que a legislação determinar, as partes que iriam decidir acerca dos montantes, conforme a sua negociação (POSNER: 1993; p. 195) (COASE: 1960; p. 7) (KLEIN: 2011; p. 71-72). Nesse caso, a única possibilidade relegada ao Direito seria deste campo prever a possibilidade de atribuir um "selo" o qual atestasse que determinado produto internaliza as externalidades, avalizando, desta maneira, a possibilidade de os agentes transacionarem no mercado acerca do preço a ser embutido no bem.

Exemplo dessa situação é a estruturação da Lei Federal n. 10.831/2003, a qual torna compulsória a certificação dos produtos orgânicos no Brasil, com exceção dos produtos vendidos diretamente pelos produtores em feiras livres, na tentativa de fomentar relações de consumo mais transparentes. Regulamentada pelo Decreto n. 6.323/2007, essa lei visa acreditar, através do Instituto Nacional de Metrologia, Normalização e Qualidade Industrial (Inmetro) ${ }^{13}$ e avalizado pelo Ministério da Agricultura, Pecuária e Abastecimento, a "certificação orgânica", que nada mais é do que a atribuição de um "selo" que "dá garantia por escrito de que uma produção ou um processo claramente identificados foi metodicamente avaliado e está em conformidade com as normas de produção orgânica vigentes" (BRASIL: 2007).

Estudos realizados sobre a produção de orgânicos certificados aduzem que estes são valorados à maior no mercado quando comparados a produtos submetidos à procedimentos comuns no âmbito da produção (TERRAZZAN; VALARINI: 2009; p. 36) ${ }^{14}$ Ademais, "a prática do sobre-preço para os produtos orgânicos [...] propicia uma melhor remuneração ao produtor, conferindo maior sustentabilidade econômica à atividade, permitindo investimentos na recuperação de recursos natu-

13 O Instituto Nacional de Metrologia, Normalização e Qualidade Industrial (Inmetro) "é uma autarquia federal, vinculada à Secretaria Especial de Produtividade, Emprego e Competitividade, do Ministério da Economia. O instituto atual como Secretaria Executiva do Conselho Nacional de Metrologia, Normalização e Qualidade Industrial (Conmetro), colegiado interministerial, que é o órgão normativo do Sistema Nacional de Metrologia, Normalização e Qualidade Industrial (Sinmetro).Objetivando integrar uma estrutura sistêmica articulada, o Sinmetro, o Conmetro e o Inmetro foram criados pela Lei 5.966, de 11 de dezembro de 1973, cabendo a este último substituir o então Instituto Nacional de Pesos e Medidas (INPM) e ampliar significativamente o seu raio de atuação a serviço da sociedade brasileira. No âmbito de sua ampla missão institucional, o Inmetro objetiva fortalecer as empresas nacionais, aumentando sua produtividade por meio da adoção de mecanismos destinados à melhoria da qualidade e da segurança de produtos e serviços" (BRASIL: 2018). 14 Inclusive, há relatos em outros países de que os produtos certificados tendem a excluir aqueles que não têm a marcação nas suas embalagens do mercado, em razão da maior competitividade e da crescente demanda qualificada por esses produtos. $C f$. SAVIN: 2006. 
rais degradados, como a recuperação de áreas de preservação permanente e reserva legal, [...] entre outros", logo, ela igualmente cumpre com o mandamento do desenvolvimento sustentável ${ }^{15}$, que é justamente a base para a criação de certificados, como aludido anteriormente (MOTTA: 2008; p. 1933).

Somando-se a essa possibilidade, também salta aos olhos a proposta introduzida por Arthur C. Pigou, o qual adota "a via de correção do mercado, [...] apostando na revalorização das preferências individuais por intermédio do Estado", em detrimento da tese Coaseana de extensão de mercado que implica em uma política de atribuição de preços (DERANI: 2009; p. 90 - grifos nossos). Ou seja, defende o autor a ideia de criação ou a isenção de impostos ou de multas pelo Estado (isto é, com a sua participação ativa) como forma de coibir ou estimular determinada conduta dentre os agentes privados (PIGOU: 1920).

Originariamente, a solução Pigouveana utilizaria apenas da "tributação extrafiscal como forma de corrigir o custo social das externalidades", pressupondo "a presença de um Estado mediador" (REALI: 2006; p. 49). Ela está assentada na concessão de incentivos, através da isenção de impostos ou na sua cobrança, que tenham o mesmo valor do custo que a externalidade representa, seja ela positiva ou negativa. Interessante lembrar que, para este autor, o agente econômico que dá ensejo a externalidade é o que arcará com os seus custos ou com os seus benefícios. ${ }^{16}$

Outrossim, essa tese permitirá o uso da ferramenta chamada de Análise Econômica do Direito $^{17}$, vez que, observando-se a limitada consistência dogmática do Direito, ressaltar-se-ia o modo em que a economia poderia contribuir para a compreensão dos problemas sociais e a própria (re)formulação das regras jurídicas. Isso, pois, na sua versão normativa, a Análise Econômica do Direito procura analisar "quais os impactos das normas legais", percebendo "as vantagens (ganhos) das normas jurídicas em face do bem-estar social, cotejando-se as consequências", com o fito de providenciar prescrições normativas para o câmbio social e/ou a reforma jurídica (ROSA: 2011; p. $61)$.

15 "Os princípios agroecológicos da produção de alimentos orgânicos contemplam o uso saudável e responsável do solo, do ar, da água e dos demais recursos naturais, evitando a contaminação e desperdícios desses elementos e contribuindo para o desenvolvimento sustentável” (NEVES: 2012; p. 27).

16 COASE, Op cit., p. 15.

17 "O desenvolvimento da AED [Análise Econômica do Direito] foi desencadeado pela criação de várias revistas científicas, com o foco específico nessa nova "disciplina". A primeira a ser lançada foi o Journal of Law and Economics, na Universidade de Chicago em 1958, cujo editor fora Aaron Director, seguido por Ronald Coase. A segunda que se tem conhecimento foi o Journal of Legal Studies, igualmente fundada na Universidade de Chicago em 1972, por Richard A. Posner. Posteriormente, outras publicações seguiram esta mesma trilha, motivando a discussão crítico-científica acerca da limitada consistência dogmática do Direito. A afirmação da AED como um importante instrumento para os cientistas jurídicos não foi tranquila. Apesar da resistência oriunda não só do direito positivo, a AED igualmente deparou-se com certa dificuldade advinda da própria Ciência Econômica por aplicar suas ferramentas em situações não dirigidas ao sistema financeiro. Entretanto, o crescente sucesso desta análise, encontra-se no próprio objeto de estudo, vez que pode auxiliar na cognição dos efeitos das regras jurídicas e a reflexão quanto aos mesmos serem aspirados socialmente, projetando sobre as suas possibilidades - o que tem atraído cada vez mais adeptos" (SQUEFF: 2016; p. 98-99). 
Essa visão de estudo, assim, tende a advogar pela formulação de novos preceitos jurídicos a partir de avaliações e recomendações de como a conduta da sociedade deveria ser para que se alcancem todos os custos de transação, respondendo às necessidades dos indivíduos (PARISI; ROWLEY: 2005; p. 39-40). Outrossim, a análise econômica não se limitaria à questão tributária como teorizou Pigou, permitindo para além da edificação de isenções ou a majoração de impostos para internalizar-se os custos socais advindos de (in)observância do desenvolvimento sustentável, a própria imposição de multas, por parte do Estado, para aqueles que não internalizarem as externalidades, particularmente, nesse caso, as negativas.

Exemplo dessa situação é a possibilidade de o Inmetro, criado pelo art. 4 da Lei Federal n. 5.966/1973 e vinculado ao atual Ministério da Indústria, Comércio Exterior e Serviços, impor sanções administrativas àqueles que descumprem as suas Portarias, as quais compõe o "sistema nacional de metrologia, normalização e qualidade industrial, com a finalidade de formular e executar a política nacional de metrologia, normalização industrial e certificação de qualidade de produtos industriais" (BRASIL: 1973).

Afinal, conforme a Lei Federal n. 9.933/1999, a qual dispõe sobre as competências do Inmetro, "[t]odos os bens comercializados no Brasil, insumos, produtos finais e serviços, sujeitos a regulamentação técnica, devem estar em conformidade com os regulamentos técnicos pertinentes em vigor", restando os mesmos sujeitos a sanções pelo seu descumprimento (BRASIL: 1999). Essas estão previstas no seu art. 8, in verbis:

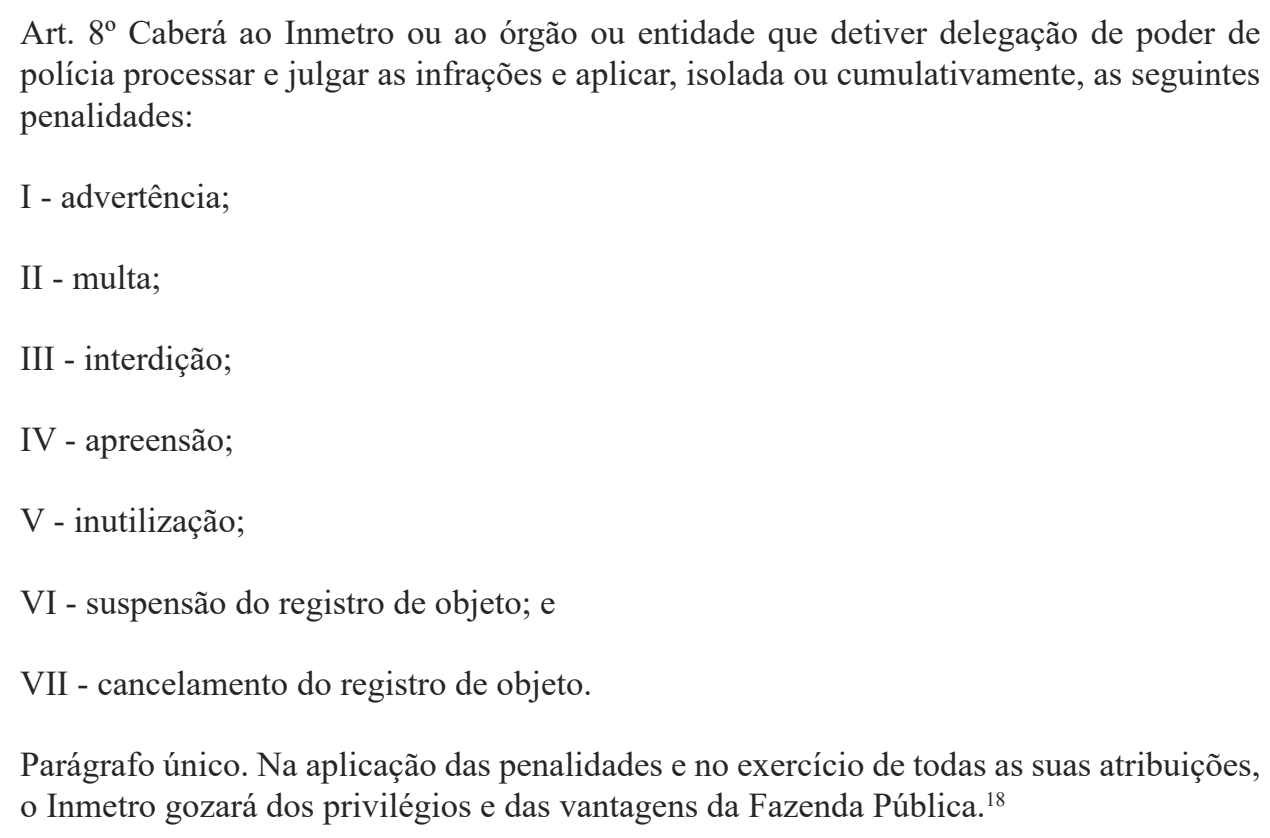

18 Cumpre, ainda, destacar o art. 9 desta mesma lei, segundo o qual "[a] pena de multa, imposta mediante procedimento administrativo, poderá variar de R \$ 100,00 até R \$ 1.500.000,00”, trazendo consigo a previsibilidade da imposição de sanção àquele que descumpre as normas técnicas deste órgão, o que, no caso, é deveras importante para a correta realização dos prós e contras por parte do produtor, estimulando, nesse caso, o cumprimento da norma pelo alto valor que poderia ser agregado à sua produção. 
Nesse caso, por terem sido criadas a partir do Estado, bem como por preverem a imposição de sanções quando descumpridas as prescrições técnicas realizadas por esse órgão as quais tem como objetivo evitar externalidades negativas, essas medidas mostram-se verdadeiras taxas Pigouveanas, servindo como exemplo da própria utilização da Análise Econômica do Direito no Brasil a partir da sua estruturação, haja vista almejar contemplar todos os custos de transação envolvidos, forjando condutas esperadas pela sociedade, as quais são garantidas pela atribuição do "selo" do Inmetro àquele que cumpre com as suas prescrições.

De toda sorte, ambas as alternativas Coaseana e Pigouveana absorveriam as externalidades nos custos de transação, sem a qual, como constata Fernando Araújo (2008; p. 139) desde uma perspectiva contratual, poder-se-iam gerar efeitos perversos, como "interferir diretamente no computo do bem-estar gerado pelas trocas, podendo chegar a inviabilizar trocas pela elementar razão de excederem em valor absoluto ao bem-estar total que as trocas gerariam", tal como a demanda qualificada tem exigido, na pós-modernidade, por critérios mais esverdeados.

Noutros termos, a importância da certificação ambiental resta observada em ambas as hipóteses, independentemente se uma ou outra for adotada por determinado país, forte na internalização das externalidades que ela gera, direcionando, ainda, a sociedade em direção de práticas mais sustentáveis. Por isso, analisada a base teórica para a sua adoção, na próxima seção serão estudados os alcances e limites da certificação ambiental, expondo-se, assim, o motivo pelo qual as certificações são relevantes na contemporaneidade.

\section{ALCANCES E LIMITES DA CERTIFICAÇÃO AMBIENTAL.}

A adequação das práticas de uma empresa a fim de obter a certificação ambiental, via de regra, não é obrigatória. Trata-se de um "ato voluntário por parte das empresas" (HEIMAN: 2015; p. 123), as quais assim o fazem a fim de obter algum benefício, particularmente quando observada a crescente conscientização da sociedade internacional acerca da importância do meio ambiente e da preservação/correta gestão dos recursos naturais para a continuidade da própria vida humana.

Assim sendo, é inegável a relação que a certificação ambiental detém com a competitividade, de modo que ela tende fomentar a adoção contínua de práticas esverdeadas pela concorrência para que estas não percam espaço no mercado de consumo diante daquele que, então, teria a posição privilegiada em razão da certificação. Afinal,

[o] grande objetivo de toda organização é ter uma forte posição competitiva, o que significa elevar as barreiras à entrada de novos competidores, engendrar um perfil de potencialidades maior e melhor do que o perfil dos seus concorrentes; tornar seu perfil compatível ou sinônimo de fatores-chave de sucesso do setor; ter um conjunto competente de estratégias competitivas inerentes; aumentar a integração ou o poder de barganha em relação aos fornecedores e intermediários e, por último, ter uma alta participação no seu segmento de mercado (TACHIZAWA; REZENDE: 2000; p. 71).

Por conseguinte, a certificação ambiental seria uma estratégia importante para que determinado produtor alcance seus objetivos de sucesso no mercado, restando à frente dos demais exatamente por obter um maior poder de barganha frente à demanda qualificada hodierna existente, gerando uma competição sadia particularmente por exigir que seus pares também adotem medidas 
semelhantes, caso busquem o mesmo tipo de destinatário, gerando um espiral de práticas sustentáveis da qual todos se beneficiam. Aliás, dessa concorrência, o próprio consumidor se beneficia, haja vista a necessidade recorrente de atualização por todos os produtores buscando ganhar mercado e, ainda, mais lucro (vez que não se pode olvidar que a raison d'être de uma empresa privada é este).

Isso sem contar a possibilidade de que, com revisões periódicas levadas a cabo pela entidade certificadora a fim de averiguar se os critérios técnicos e organizacionais previamente estipulados (e que igualmente fundamentaram a atribuição do "selo") estão sendo seguidos ${ }^{19}$, a empresa também age preventivamente, reduzindo a possibilidade de incorrer em custos negativos adicionais, seja pela ocorrência de danos, seja pela imposição de sobretaxas pelo Poder Público. Ou ainda, em razão das auditorias periódicas, seria mais fácil a empresa obter benefícios junto ao Estado quando as isenções fiscais estiverem ao alcance do empreendedor que age de maneira ambientalmente correta e consegue comprovar periodicamente as suas ações/atualizações (VALLE: 2004; p. 38-39).

E nesse cenário, quem ainda ganha é o consumidor, o qual é guarnecido por informações as quais lhe permite realizar escolhas apoiadas e lúcidas, dentre as diversas opções existentes no mercado. Até mesmo porque, não existem escolhas neutras. "As escolhas de indivíduos racionais sempre buscam maximizar seus próprios interesses e o seu bem-estar (também chamado de utilidade). Em outras palavras, a utilidade traduz a satisfação dos indivíduos associada aos resultados em potencial oriundos de suas escolhas" (RAMOS; SQUEFF: 2019; no prelo), o que, no cenário ambiental, poderia ser evitar a exaustão dos recursos naturais e inexistirem impactos à saúde humana, para citar alguns (CAVALIERI FILHO: 2015; p. 6) (MARQUES: 2006; p. 147).

Nesse sentido, a certificação ambiental assume um papel importante para a efetivação plena do princípio da informação, tido como elemento basilar do Direito do Consumidor por garantir o estabelecimento do próprio juízo do consumidor sobre determinado item a partir do que lhe é fornecido, de modo que ele ponderará acerca da compra do bem quando conhecer de forma clara os seus componentes (CAVALIERI FILHO: 2015; p. 6) (MARQUES: 2006; p. 147). ${ }^{20}$ Em que pese seja esse um dever já reconhecido ao fornecedor (ao menos no Brasil, em razão do art. 4, inc. IV, do Código de Defesa do Consumidor), quanto maiores informações este prestar, mais fácil será a escolha a ser realizada pelo consumidor (BARBOSA: 2009; p. 17).

Não só isso, a certificação colabora para a própria diminuição da vulnerabilidade informacional dos consumidores (AGUIAR; TRENTINI: 2014; p. 67). Em que pese ser compreendida como uma subespécie da vulnerabilidade fática do consumidor, trata-se de uma nova categoria, própria da sociedade da informação, “em que o acesso às informações do produto e a confiança despertada em razão da comunicação e da publicidade, colocam o consumidor em uma posição passiva e sem condições, a priori, de atestar a veracidade dos dados" (MIRAGEM: 2010; p. 68). Consequentemente, a existência de um "selo" na embalagem de certo produto torna-se uma forma de ajudar o consumidor, posto que a veracidade será afiançada por uma autoridade fiscalizadora.

19 Sobre as auditorias ambientais e potenciais problemas que elas podem empregar, vez que não estariam sujeitos, a priori, ao controle estatal (externo), (cf. PEREIRA: 1999).

20 Essa percepção, defendida principalmente por Gary Becker, defende uma conduta que maximiza os benefícios individuais, permitindo que eles façam suas escolhas racionalmente em um momento específico, de acordo com suas preferências atuais e condições/ambiente. (Cf. BECKER: 1976; cap. 8). 
Outrossim, mesmo diante de alcances tão positivos, é possível dizer que a certificação ambiental também encontra limites, particularmente pela pluralidade de opções de certificados existentes no mercado. Afinal, não são apenas os Estados que por meio de legislações domésticas criam "selos", como também existem ambientes supranacionais e entidades privadas que igualmente o fazem, logo, tornando impossível que um determinado produto receba as mais diversas certificações haja vista o alto custo que estaria envolvido para a adaptação da produção consoante o regulamento de cada ente, o qual teria um valor muito elevado como consequência ${ }^{21}$ (fomentando uma 'desvantagem comparativa').

No plano internacional, a certificação ambiental mais conhecida é aquela fornecida pela International Standardization Organization (ISO), organização não-governamental constituída em 1946 em Genebra (Suíça), da qual o Brasil participa por intermédio da Associação Brasileira de Normas Técnicas (ABNT), chamada de "ISO 14000", as quais foram edificadas a partir da já citada Agenda 21, formulada no ano de 1992 por ocasião da Cúpula da Terra (RIBEIRO: 2005; p. 53).

A estrutura da ISO 14000 aborda, entre outras questões, basicamente aspectos relacionados à certificação dos sistemas de gestão ambiental das empresas e de sítios e a forma como as informações ambientais são apresentadas aos consumidores, através da rotulagem de produtos. [...] [N]o decorrer do desenvolvimento das normas da série ISO 14000, buscouse assegurar que estas estivessem relacionadas à padronização de processos, e não ao estabelecimento de parâmetros de desempenho ambiental, os quais, por sua vez, são atribuíveis unicamente à legislação ambiental. Em virtude disso, essas normas apresentam, em linhas gerais, os elementos necessários à construção de um sistema que alcance as metas ambientais estabelecidas pela organização (VIDIGAL: 2012; p. 5051-5052).

A família 'ISO 14000' é composta por várias normas, as quais a empresa poderá escolher vincular-se a fim da obtenção do "selo" desta entidade, dentre as quais se citam:

ISO 14001: trata do Sistema de Gestão Ambiental (SGA), sendo direcionada à certificação por terceiras partes.

ISO 14004: trata do Sistema de Gestão Ambiental, sendo destinada ao uso interno da Empresa, ou seja, corresponde ao suporte da gestão ambiental.

ISO 14010: são normas sobre as Auditorias Ambientais. São elas que asseguram credibilidade a todo processo de certificação ambiental, visando as auditorias de terceiras partes, nas quais se verificam os compromissos estabelecidos pela empresa em seu Sistema de Gestão Ambiental.

ISO 14031: são normas sobre Desempenho Ambiental, que estabelecem as diretrizes para medição, análise e definição do desempenho ambiental de uma organização, a fim de assegurar o SGA.

ISO 14020: são normas sobre Rotulagem Ambiental, estabelecendo orientações para a expressão das características ambientais dos produtos das empresas, de forma que os rótulos ressaltem as características ambientais do produto.

ISO 14040: são normas sobre a Análise do Ciclo de Vida, estabelecendo as interações entre as atividades produtivas e o meio ambiente. Analisa o impacto causado pelos produtos, processos e serviços relacionados desde a extração dos recursos naturais até a disposição final (SILVA; OHARA; GHIZZI, s/d.).

21 Sobre o tema, $c f$. SILVA: 2018. 
No caso, para receber o "selo" da ISO em qualquer uma das modalidades descritas, a empresa deverá cumprir os requisitos elencados pela entidade, os quais contemplam, de maneira reduzida, “1) a elaboração da política ambiental [da empresa]; 2) o planejamento [acerca da aplicação do sistema escolhido] ; 3) a implementação e operação [da normativa]; 4) a verificação e ação corretiva [caso houver]; 5) a análise crítica pela administração" - "que não cessa, devendo retornar ao (1) no sentido de uma espiral em constante movimento, sendo a obrigatoriedade quanto à melhoria contínua o seu propulsor/movimentador" (CORRÊA: 2006; p. 195). Ou seja, o empreendedor deverá estar em constate conformação para com tais requisitos, de modo que ele está fadado a perder a certificação caso não desprenda a atenção necessária.

Logo, imaginar que além da ISO existe ainda uma pluralidade de "selos" disponíveis no mercado, sejam eles de ordem doméstica, como o "selo" Blau Engel da Alemanha, o BS 7750 inglês, o Green Seal e o Forest Sterwadship Council americanos, ou, ainda, outros de ordem supranacional, como o ecolabel europeu forjado a partir do Regulamento n. 1836/9322, faz com que isso gere uma competição entre as próprias entidades, cabendo a cada produtor averiguar qual das certificações melhor lhe serve à luz de sua estratégia empresarial e do seu público-alvo, não sendo possível abranger todas as modalidades existentes.

Com isso, por mais que este seja um modelo de gestão ambiental interessante e favorável para a própria empresa ao internalizar as externalidades com as quais ela arcava diretamente (ou as repassava ao consumidor de maneira indireta), tornando mais claro ao destinatário final o que este está pagando ao adquirir o seu bem, efetivando-se, assim, o princípio da informação, assim como lhe permite utilizar dessa plataforma de certificação como meio de expandir os negócios à luz das demandas cada vez mais crescentes por produtos ambientalmente corretos e sustentáveis, não se pode negar que a pluralidade e a descentralização da distribuição dos "selos" não é benéfico, posto que mesmo com a própria obtenção de um certificado, o qual já apresenta certo custo, o efeito esperado pode não ocorrer, terminando por diminuir a competitividade que em um primeiro momento ela parecia fomentar, assim como, possivelmente, a própria sustentabilidade produtiva e de consumo. ${ }^{23}$

\section{CONCLUSÃO}

O presente escrito tinha como objetivo estudar a certificação ambiental, desde as suas origens até o seu uso na contemporaneidade, almejando verificar se essa poderia ser considerada, ao fim e ao cabo, uma ferramenta capaz de não só colaborar para que se atinjam os padrões de sustentabilidade que a pós-modernidade imprime, especialmente quanto ao desenvolvimento e o consumo, como também se promova a nova racionalidade ecológica desenvolvida ao largo de décadas de debate no campo do Direito Ambiental Internacional.

22 Para uma explicação sobre essas certificações, $c f$. VIDIGAL: 2012; p. 5050-5062. Para outras, no ambiente latino americano, $c f$. HEIMANN; PIRES; POSONSKI: 2015; p. 123-124.

23 Para outros efeitos negativos, particularmente em relação aqueles que não possuem a certificação, $c f$. AZEVEDO: 2005; p. 122-123. 
E à luz do exposto, é possível concluir que os "selos" colaboram, sim, para a realização da gestão ambiental em prol da sustentabilidade. Afinal, as certificações ambientais permitem que não apenas se internalize nos custos de transação de bens as externalidades positivas as quais eles geram, como também são um mecanismo importante para a promoção da consciência ambiental, particularmente, de que devem ser adotadas medidas para evitar a ocorrência do uso desenfreado dos recursos naturais, garantindo não só o seu uso e gozo pelas gerações atuais como também pelas futuras, assim como para buscar a realização de práticas socialmente sustentáveis nas fases de produção, de consumo e de pós-consumo.

Até mesmo porque, as certificações ambientais seriam instrumentos positivos de conduta social, os quais permitiriam, ainda, a empresa atingir o seu maior objetivo que é o lucro, seja majorando o preço do seu bem devidamente certificado consoante a tese de Coase, seja pela não imposição de uma multa pelo descumprimento das normativas técnicas da entidade certificadora consoante a tese de Pigou, em que pese ela promova igualmente a adoção de mecanismos ambientalmente e socialmente sustentáveis, voltados a suprir uma demanda cada vez mais qualificada (e racional quanto ao exaurimento dos bens ambientais e da necessidade de adotar-se medidas esverdeadas), fazendo com que todas as partes envolvidas obtenham um resultado positivo e colaborem para um cenário maior, que é a própria preservação da espécie humana.

Assim, tem-se que os "selos", quando adotados pelo produtor, incentivam tanto na esfera doméstica quanto internacional a proteção indireta dos espaços comuns, em uma verdadeira revalorização dos mesmos com base na importância que estes detêm não só na produção econômica em si, como também para a sociedade em geral. Ademais, eles fomentam a concorrência sadia entre os diversos produtores de um determinado bem de consumo e garantem uma maior atenção à prevenção de danos, evitando outras consequências que poderiam emergir da desatenção do meio ambiente e da sociedade pela atividade econômica.

Além disso, considerando que a sociedade pós-moderna é uma sociedade de consumo extremamente interligada, a possibilidade que a certificação traz no tocante a aumentar a informação repassada aos consumidores é outro ponto alto da sua utilização. Não só por efetivamente possibilitar uma diminuição da vulnerabilidade informacional, como também por permitir uma decisão verdadeiramente apoiada, com base naquilo que o consumidor qualificado racionalmente busca hodiernamente - a sustentabilidade -, os "selos" mostram-se essenciais. A única questão, porém, que parece ainda restar em aberto é justamente a existência de diversas entidades passíveis de certificar os produtores, pois, de fato, a pluralidade pode ter um efeito contrário, terminando por prejudicar a viabilidade econômica do empreendimento, gerando consequências diretas nas demais áreas do tripé do desenvolvimento sustentável, sendo esse um ponto ainda aberto a debates.

\section{REFERÊNCIAS}

AGUIAR, Carolina C.; TRENTINI, Flávia. O papel da certificação na proteção ambiental realizada pela atividade agrária. Revista da Fac. Dir. UFG, Goiânia, v. 38, n. 2, pp. 57-79, jul./dez. 2014.

ARAUJO, Fernando. Uma Análise Econômica do Contrato: a abordaem econômica, a responsabilidade e a tutela dos interesses contratuais. In: TIMM, Luciano Benetti (org.). Direito e Economia. Porto Alegre: Livraria do Advogado, 2008. 
AZEVEDO, Paulo Furquim de. Economia dos contratos. In: ZYLBERSZTAJN, Decio; SZTAJN, Rachel (Org.). Direito \& Economia: análise econômica do direito e das organizações. Rio de Janeiro: Elsevier, pp. 102-136, 2005.

BARBOSA, Fernanda Nunes. Informação: direito e dever nas relações de consumo. São Paulo: RT, 2009.

BECKER, Gary S. The Economic Approach to Human Behavior. Chicago: University of Chicago Press, 1976.

BRASIL. Decreto n. 6.323. 2007.

BRASIL. Lei Federal n. 10.831. 2003.

BRASIL. Lei Federal n. 5.966. 1973.

BRASIL. Lei Federal n. 9.933. 1999.

BRASIL. Ministério do Meio Ambiente. Agenda 21 Global. Brasília, s/d. Disponível em: http://www.mma. gov.br/responsabilidade-socioambiental/agenda-21/agenda-21-global.html. Acesso em 18 fev. 2019.

BRASIL. Inmetro: Institucional. Brasília, 5 set. 2018. Disponível em:www4.inmetro.gov.br/acesso-a-informacao/institucional. Acesso em: 10 dez. 2019.

BRETON, Tony. The Greening of Machiavelli: the evolution of international environmental politics. London: RIIA, 1994.

CALGARO, Cleide. Sustentabilidade, Racionalidade e Consumo: As Faces do Poder. Anais do IV Seminário de Turismo do Mercosul. GT "Recursos Naturais e o Turismo". Caxias do Sul, 7-8 jul. 2006. Disponível em: https://www.ucs.br/ucs/tplSemMenus/eventos/seminarios_semintur/semin tur_4/arquivos_4_seminario/ GT05-5.pdf. Acesso em: 18 fev. 2019.

CARVALHO, Cristiano; JOBIM, Eduardo. O Direito Tributário e a interpretação econômica do Direito: everes instrumentais, custos de conformidade e custos de transação. In: TIMM, Luciano Benetti (org.). Direito e Economia. Porto Alegre: Livraria do Advogado, 2008.

CARVALHO, Edson Ferreira. Meio Ambiente e Direitos Humanos. 2 ed. Curitiba: Juruá, 2011.

CAVALIERI FILHO, Sergio. Programa de Direito do Consumidor. 4 ed. São Paulo: Atlas, 2015.

CLAPP, Jennifer; DAUVERGNE, Peter. Paths to a Green World: The Political Economy if the Global Environment. Boston: MIT, 2005.

COASE, Roland. The Problem of Social Cost. The Journal of Law and Economics. v. 3, n.1, pp. 1-44, oct. 1960.

COASE, Roland. El problema del Costo Social. In: ROEMER, Andrés (comp.). Derecho y Economía: una revisión de la literatura. México D.F.: Centro de Estudios de Gobernabilidad y Políticas Publicas, 2000.

CORRÊA, Daniel Rocha. Certificação ambiental, desenvolvimento sustentável e barreiras à entrada. Revista de Informação Legislativa, Brasília, a. 43, n. 169, pp. 189-201, jan./mar. 2006.

D'AMATO, Anthony; ENGEL, Kirsten. International Environmental Law Anthology. Cincinnati: Anderson publications, 1997.

DERANI, Cristiane. Direito Ambiental Econômico. 3 ed. São Paulo: Saraiva, 2009,

FARINA, Elizabeth M. Padronização em sistemas agroindustriais. In: ZYLBERSZTAJN, Décio; SACRE, Roberto F. (Orgs). Gestão de qualidade no Agribusiness: estudos e casos. São Paulo: Atlas, pp. 18-29, 2003.

FRIEDMAN, David. Direito e Ciência Econômica. Revista Sub Judice: justiça e sociedade. Lisboa, n.2, pp. 31-38, jan./abr. 1992.

GERHARDT, Tatiana E.; SILVEIRA, Denise T. (Orgs.). Métodos de Pesquisa. Porto Alegre: Editora da UFRGS, 2009.

GUERRA, Sidney. Curso de Direito Internacional Público. $4^{\mathrm{a}}$ ed. Rio de Janeiro: Lúmen Juris, 2009. 
GUERRA, Sidney. Direito Internacional Ambiental. Rio de Janeiro: Freitas Bastos ed., 2006a.

GUERRA, Sidney. Estado e Direitos Humanos em tempos de Crise. Curitiba: Instituto Memória, 2018.

GUERRA, Sidney. Globalização na Sociedade de Risco e o Princípio da Não Indiferença em matéria ambiental. In: GUERRA, Sidney (Org.). Globalização: desafios e implicações para o Direito Internacional Contemporâneo. Ijuí: Unijuí, pp. 435-458, 2006 b.

GUERRA, Sidney. GUERRA, Caio Cesar Grande. Desenvolvimento Sustentável à luz do Direito Internacional Ambiental. In: MENEZES, Wagner; MOSCHEN, Valeska Raizer B. [Orgs.]. Direito internacional. Florianópolis: FUNJAB, pp. 229-25, 2013.

GIDDENS, Anthony. As consequências da modernidade. São Paulo: Ed. UNESP, 1991.

HARRISON, Jeffery L. Law and Economics in a Nutshell. $2^{\text {nd }}$ ed. St. Paul: West Group, 2000.

HEIMANN, Jaqueline de Paula; PIRES, Paulo de Tarso; POSONSKI, Marcelo. Novos desafios da certificação ambiental na América Latina. Planeta Amazônia - Revista Internacional de Direito Ambiental e Políticas Públicas. Macapá, n. 7, pp. 115-127, 2015.

KLEIN, Vinicius. Teorema de Coase. In: KLEIN, Vinicius; RIBEIRO, Márcia Carla P. O que é Análise Econômica do Direito: uma introdução. Belo Horizonte: Ed. Forum, 2011.

LAGO, André Cunha. Estocolmo, Rio, Johanesburgo: O Brasil e as Três Conferências Ambientais das Nações Unidas. Brasília: FUNAG, 2007.

LIMA, Gabriela Garcia B. O pluralismo jurídico e efetividade jurídica na relação entre proteção ambiental e investimentos estrangeiros: os casos Santa Elena, Metalclad e Tecmed. Revista de Direito Internacional, Brasília, v. 9, n. 4, pp. 27-57, 2012.

MARQUES, Claudia Lima. Contratos no código de defesa do consumidor: o novo regime das relações contratuais. 5 ed. São Paulo: RT, 2006.

MIRAGEM, Bruno Barbosa. Curso de Direito do Consumidor. 2 ed. São Paulo: RT, 2010.

MOTTA, Ivo de Sá et al. Análise econômica da produção do Maracujazeiro amarelo em sistemas orgânico e convencional. Ciência e Agrotecnologia, Lavras, v. 32, n. 6, pp. 1927-1934, dez. 2008.

NUSDEO, Fábio. Curso de Economia: Introdução ao Direito Econômico. 6 ed. São Paulo: RT, 2010.

NEVES, Daniel Almeida L. Escolhas estratégicas para produção de carne bovina orgânica no Brasil. Dissertação de Mestrado - Faculdade de Agronomia e Medicina Veterinária, Universidade de Brasília. 141p. Brasília: UnB, 2012

NUNES, Mônica F. Análise da contribuição das certificações ambientais aos desafios da Agenda 2030. Revista Internacional de Ciências, Rio de Janeiro, v. 8, n. 01, pp. 27-46, jan./jun. 2018

ONU. Declaração de Estocolmo. 1972.

ONU. Resolução 44/228. 1989

PARISI, Francesco; ROWLEY, Charles K. The Origins of Law and Economics: essays by the founding fathers. Cheltenham: Edward Elgar, 2005.

PEREIRA, Romilson Rodrigues. Instrumentos de Política Ambiental: a auditoria ambiental. Revista do Tribunal de Contas da União, Brasília, v. 30, n.79, pp. 82-91, 1999.

PIGOU, Arthur C. The Economics of Welfare. New York: Macmillan, 1920.

POSNER, Richard A. Nobel Literature: Ronald Coase and methodology. Journal of Economic Perspectives. v. 7, n. 4, pp. 195-210, Autumm 1993.

RAMOS, Fabiana D'Andrea; SQUEFF, Tatiana Cardoso. The Importance of Labelling Food Items: Information, Food Security and Sustainable Consumption. In: AMARAL Jr, Alberto do;

VIEIRA, Luciane Klein; ALMEIDA, Lucila. Sustainable Consumption: The Right to a Healthy Environment. 
Basel: Springer, 2019 (no prelo).

REALI, Darci. Os municípios e a tributação ambiental. Caxias do Sul: Educs, 2006.

RIELSKI, Ana Carolina. ISSO 14001 e a sustentabilidade: A eficácia do instrumento no alcance do desenvolvimento sustentável. São Paulo, USP - Faculdade de Economia e Administração, s/d. Disponível em: $<$ https://www.usp.br/mudarfuturo/cms/?p=212>. Acesso em: 26 fev. 2019.

ROSA, Alexandre Morais. The Road of Serfdom: Law and Economics. In: ROSA, Alexandre Morais; LINHARES, José Manuel Aroso. Diálogos com a Law and Economics. $2^{\mathrm{a}}$ ed. Rio de Janeiro: Lumen Juris, 2011.

RIBEIRO, Wagner Costa. A ordem ambiental internacional. São Paulo: ed. Contexto, 2005.

ROWLAND, Wade. The Plot to Save the World. Toronto: Clarke, Irwin \& Co. Ltd, 1973.

SALAMA, Bruno Meyerhof. O que é "Direito e Economia"? In: TIMM, Luciano Benetti (org.). Direito e Economia. Porto Alegre: Livraria do Advogado, 2008.

SALZMAN, James. Sustainable Consumption and the Law. Environmental Law, n. 27, pp. 1243-1293, 1997.

SAVIN, Glaucia. Embalagens - Tendências da responsabilização ambiental. Consultor Jurídico, São Paulo, 18 set. 2006. Disponível em: $<$ https://www.conjur.com.br/2006-set-18/embalagens tendencias_responsabilizacao_ambiental> . Acesso em: 26 fev. 2019.

SILVA; Alexandre R.; OHARA, Luis Fernando; GHIZZI, Maria Luiza P. Normas Iso 14000: Sistema de Gestão Ambiental. São Paulo, USP - Escola Superior de Agricultura “Luiz de Queiroz", s/d. Disponível em: $<$ www.qualidade.esalq.usp.br/fase2/iso14000.htm>. Acesso em: 26 fev. 2019.

SILVA, Eliane. "Certificação atrapalha produtores de orgânicos", diz representante do Slow Food. Revista Globo Rural, Porto Alegre/Rio de janeiro, 24 set. 2018. Disponível em: $<$ https://revistagloborural.globo. com/Noticias/Sustentabilidade/noticia/2018/09/selo-de-organicos-so-atrapalha-produtores-diz-representante-do-slow-food.html >. Acesso em: 02 mar. 2019.

SILVEIRA, Gustavo Madeira; AMARAL, Renata Campetti. Créditos de redução de emissões transacionáveis: um estudo sob a ótica de Coase. In: In: TIMM, Luciano Benetti (org.). Direito e Economia. Porto Alegre: Livraria do Advogado, 2008.

SQUEFF, Tatiana Cardoso. Análise Econômica do Direito Ambiental: perspectivas internas e internacional. Rio de Janeiro: Lúmen Juris, 2016.

TACHIZAWA, Takeshy; REZENDE, Wilson. Estratégia Empresarial: tendências e desafios. São Paulo: Makron Books 2000.

TERRAZZAN, Priscila; VALARINI, Pedro José. Situação do Mercado de Produtos Orgânicos e as Formas de Comercialização no Brasil. Informações Econômicas, São Paulo, v. 39, n. 11, pp. 29-41, nov. 2009.

TRINDADE, Antônio A. Cançado. Direitos Humanos e Meio Ambiente. Porto Alegre: SAFE, 1993.

TURNER, R. Kerry; PEARCE, David; BATEMAN, Ian. Environmental Economics: an elementary introduction. Baltimore: John Hopkins University Press, 1993.

VALLE, Cyro E. Qualidade ambiental: ISO 14000. 5 ed. São Paulo: Ed. SENAC, 2004.

VIDIGAL, Inara de Pinho. A certificação ambiental como instrumento para a competitividade econômica e o desenvolvimento sustentável. Anais do XXI Encontro Nacional do CONPEDI. Florianópolis/Uberlândia: Fundação Boiteux/UFU, pp. 5039-5067, 2012.

YU, Chang Man. Sequestro Florestal de Carbono no Brasil. São Paulo: Annablume/IEB, 2004. 
Data de submissão do artigo: Março de 2019

Data de aceite do artigo: Março de 2020(*)

\section{(*) NOTA TÉCNICA:}

Esclarecemos que, em razão do ataque de hackers a que foi submetido o conjunto de periódicos da Universidade Federal de Goiás (UFG), ao que se inclui a Revista da Faculdade de Direito da UFG (RFD/UFG), os artigos ordenados entre os números 21-30, referentes ao volume 43, embora tenham sido recebidos e aceitos em datas distintas e anteriores, dado o perecimento de suas referências, foram todos registrados com o expediente de aceite no mês de março de 2020. 